\title{
Resource allocation approach to associate business-IT alignment to enterprise architecture design
}

\author{
ZHANG Mengmeng*, CHEN Honghui, and LIU Junxian \\ Science and Technology on Information Systems Engineering Laboratory, National University of Defense Technology, \\ Changsha 410072, China
}

\begin{abstract}
Enterprise architecture (EA) development is always a superior way to address business-IT alignment (BITA) issue. However, most EA design frameworks are inadequate to allocate IT resources, which is an important metric of BITA maturity. Under this situation, the idea of IT resource allocation is combined with the EA design process, in order to extend prior EA research on BITA and to demonstrate EA's capability of implementing IT governance. As an effective resource allocation method, portfolio decision analysis (PDA) is used to align business functions of business architecture and applications of system architecture. Furthermore, this paper exhibits an illustrative case with the proposed framework.
\end{abstract}

Keywords: business-IT alignment (BITA), enterprise architecture (EA), IT resource allocation, portfolio decision analysis (PDA).

DOI: $10.21629 / J S E E .2019 .02 .13$

\section{Introduction}

The importance of business-IT alignment (BITA) has been well known since the 1990s [1-5]. Over the past several decades, it persists among the top-ranked concerns of business and IT executives, contributing to "maximizing the return value of IT investments", "providing direction and flexibility to react to change", and "improving organizational performance" [6]. Significant progress has been made to address BITA in recent years, mainly from BITA measurement [7 -9], BITA evolution [10-12], enterprise architecture (EA) development [13-15], and BITA's relations with relevant fields [16-18]. Among them, EA is a methodology to effectively align the strategies of enterprises together with their processes and resources (business and IT) $[19,20]$. It is a superior method to achieve BITA [21].

In general, BITA should be well supported through effective EA design processes [13,21,22]. Considering the

\footnotetext{
Manuscript received December 25, 2017.

*Corresponding author.

This work was supported by the National Natural Science Foundation of China (71571189).
}

six maturity criteria proposed by Luftman [7], and comparatively analyzing them with EA research on BITA, we have identified that the "IT governance" criterion received the least attention. IT governance emphasizes the formal discussion and review for priorities and allocation of IT resources by appropriate business and IT participants [7]. Several EA papers explained IT governance from a descriptive way, rather than proposed specific governance methods $[21,22]$.

To better support BITA with EA methods, the IT resource allocation issue is mainly considered from the EA domain. This issue demands IT resources should be allocated in IT systems to satisfy business requirements at a lower cost and a higher efficiency. Without loss of generality, this paper involves the resource allocation between business functions and applications [13,23]. We seek to answer the following research question: how can we apply resource allocation analysis to the EA design process and achieve a better alignment between business functions and applications?

To address this question, we will first discuss the importance of IT resource allocation in the development of EA. In addition, a portfolio decision analysis (PDA) approach is introduced in the process of EA design. Furthermore, we exhibit an illustrative Switcher system architecture (SA) case to explain the application of the proposed method. An important theoretical and methodological novelty that we present in this work is a resource allocation contribution to identify and mitigate the weak point of BITA achievement with regard to the EA research.

\section{Related works}

\subsection{BITA achievement with EA}

Generally, EA exhibits its advantages in aligning business and IT by developing architecture frameworks and models [21,22]. Various viewpoints and corresponding artifacts are considered in the EA frameworks [23,24]. A successful EA research should support each aspect of BITA. 
To analyze the extant EA research on BITA, we select representative EA studies and compare them with Luftman's six maturity criteria. The mappings are displayed in Table
1. These articles have been chosen because either they have been widely cited, or they provide a particular perspective on BITA.

Table 1 Comparative analysis between representative EA studies and BITA maturity criteria

\begin{tabular}{|c|c|c|c|c|c|c|}
\hline \multirow[b]{2}{*}{ Source } & \multicolumn{6}{|c|}{ Luftman's six alignment maturity criteria } \\
\hline & Communications & $\begin{array}{c}\text { Competence/value } \\
\text { measurements }\end{array}$ & IT governance & Partnership & $\begin{array}{c}\text { Scope \& } \\
\text { architecture }\end{array}$ & Skills \\
\hline Buchanan and Soley (2002) [30] & $\bar{\circ}$ & - & - & $\overline{0}$ & $\bullet$ & $\overline{0}$ \\
\hline Zarvic and Wieringa (2006) [14] & $\bullet$ & - & - & - & ○ & - \\
\hline Wegmann, et al. $(2005,2007)[19,20]$ & $\circ$ & $\bullet$ & - & $\bullet$ & $\circ$ & - \\
\hline Plazaola, et al. (2007) [22] & $\circ$ & $\circ$ & $\circ$ & $\circ$ & $\circ$ & $\circ$ \\
\hline Wang, et al. (2008) [25] & $\circ$ & $\circ$ & $\circ$ & - & $\circ$ & - \\
\hline Saat, et al. (2010) [21] & $\circ$ & $\bullet$ & $\circ$ & $\circ$ & $\circ$ & $\circ$ \\
\hline Fritscher and Pigneur (2011) [32] & $\circ$ & $\circ$ & - & $\circ$ & $\bullet$ & $\circ$ \\
\hline Iacob, et al. (2012) [29] & $\circ$ & $\bullet$ & $\bullet$ & $\circ$ & $\bullet$ & $\circ$ \\
\hline Hiukelmann and Pasquini (2014) [33] & $\bullet$ & - & - & $\circ$ & $\bullet$ & $\circ$ \\
\hline Hinkelmann, et al. (2016) [15] & $\bullet$ & $\circ$ & - & ○ & $\bullet$ & - \\
\hline Malta and Sousa (2016) [26] & ० & ० & ० & $\circ$ & ० & - \\
\hline
\end{tabular}

As shown in Table 1, ○ means the criterion is not included in a detailed form, $\bullet$ means the criterion is included in a detailed form, and - means the criterion is not included in the research. According to Table 1, all the criteria have been studied in the studies, while IT governance has acquired the least analysis. The six studies that involve IT governance are discussed as follows. Plazaola et al. explored how and where to collect EA data and measured BITA with the above six criteria [22]. Wang et al. proposed an open group architecture framework (TOGAF) development process which included EA design and governance implementation [25]. Saat et al. presented a meta-model method (a high-level abstraction of architecture contents) by considering tangible qualities of IT systems, business, and IT governance [21]. Malta and Sousa discussed that BITA should be achieved and maintained in an efficient and sustainable way [26]. Öri deemed IT governance as a part of BITA measurement and mapped it to the EA metamodel $[27,28]$. The above five studies examined IT governance from a descriptive perspective. Addtionally, Iacob et al. extended the Archimate meta-model to represent strategy and value related concepts, and introduced a binary integer programming model to minimize systems maintenance and implementation costs for new connections among the systems [29]. This article executes a beneficial attempt on resource allocation. Insufficiently, all the above authors did not provide a detailed process of how to apply resource allocation to the EA design process, which can facilitate developing a deeper understanding of BITA achievement with EA and making their combination more practical.

IT resource allocation is always a key component of IT governance. Luftman argued that IT governance con- tained strategic planning, budgetary control, IT resource allocation, and so on [7]. He also pointed out that the IT resource allocation was among the most important enablers/inhibitors of alignment [7]. We mainly discuss IT resource allocation to bridge EA development with BITA achievement. And a PDA method, which has been widely used to resource allocation issues of government, medical, and military fields, is introduced here.

\subsection{PDA}

The resource allocation problem is ubiquitous in organizations. It mainly represents the contradiction between abundant projects and limited investments. Scholars have proposed different resource allocation methods in the studies, such as the financial resource optimization $[34,35]$, project selection [35,36], innovation portfolio management [37], and PDA [35,38].

Among these methods, PDA refers to a body of theory, methods, and practices which seeks to help decisionmakers make multiple informed selections from a discrete set of alternatives through mathematical modeling that accounts for relevant constraints, preferences, and uncertainties [35]. With regard to the research on PDA, the Systems Analysis Laboratory at Aalto University has conducted considerable studies. Salo and his colleagues issued a book to explain PDA's definition, source, quality framework, and relevant techniques [35]. To meet incomplete information, Liesiö et al. proposed a robust portfolio modeling [38] and a scenario-based portfolio selection [39]. In order to validate the PDA's feasibility, Salo and Liesiö applied PDA in a Scandinavian research program [40] and a telecommunication company [41]. Kangaspunta et 
al. discussed the weapon system portfolio through a costefficient analysis [42]. Overall, the maturity and practicability of PDA increase along with the growing attention on this topic.

Comparing the features of PDA with our initiatives, we argue that business requirements can be regarded as decision goals and IT contents can be discrete alternatives. Considering the constraints, budgets and costs among them, PDA can be suitably used to select IT portfolios to meet business requirements in a cost-efficient way.

\section{Method description}

Various alignment patterns exist in EA layers or among different EA layers. In this section, we first introduce an alignment pattern which displays the fit between business functions and applications, then we apply PDA to this alignment and propose an integrated framework with EA design process.

\subsection{Question presentation}

To describe a complex organization, EA is used to include multiple layers, and not limited to the business architecture layer (e.g., capabilities, business processes, business functions), the information system architecture layer (e.g., applications, application services, data structures), and the technology architecture layer (e.g., software, hardware, networks) $[13,23]$. Achieving alignments relating to these layers results in different EA design methods. Fig. 1 illustrates the development process of TOGAF [43], which includes the EA design stage, the transition planning stage, and the governance implementation stage. The EA design stage includes the development of business architecture, information system architecture and technology architecture.

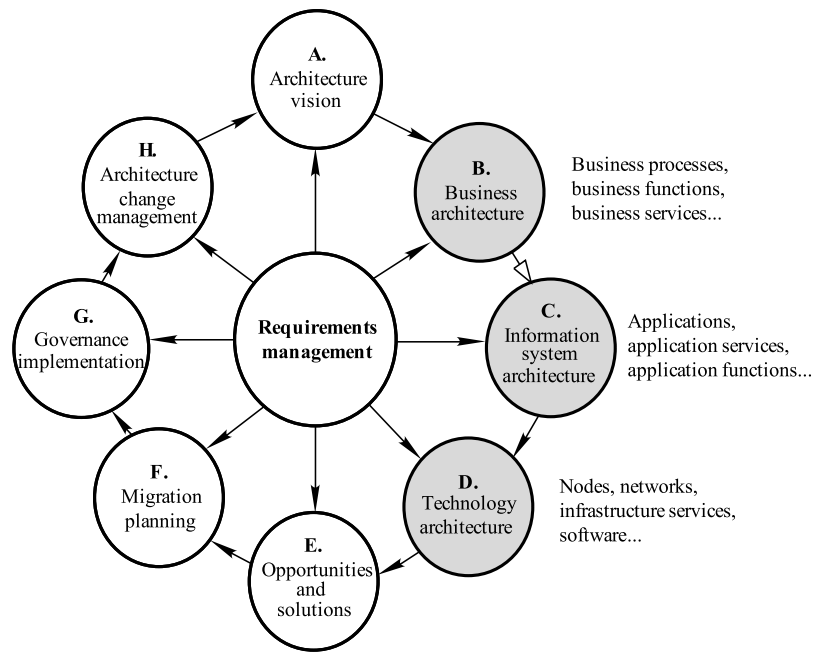

Fig. 1 TOGAF development process
Various alignment patterns exist in this stage, such as the alignments between business processes and applications, business functions and applications, business services and application functions, and so on [44].

Without loss of generality, we mainly analyze the alignment between business functions and applications. This kind of alignment can reflect the correlation and dependency between business architecture and information system architecture (hollow arrow in Fig. 1). Generally, a business function is a description of work that is performed to accomplish business units' responsibilities. An application is a building block to provide abilities for fulfilling business actions. From the perspective of IT resource allocation, this alignment issue seeks to select application portfolios with limited resources in the searching for business functions.

Practically, the applications in information system architecture are often redundant and complex because of the legacy ones [45]. To align business functions and applications from the perspective of resource allocation, the following questions should be discussed: (i) How can we gather complete business functions and applications in the EA design process? (ii) How can we integrate an alignment model between business functions and applications? (iii) How can we obtain the cost-efficient application portfolios to support business functions? Under this situation, business functions can act as decision goals, and applications as discrete alternatives. Therefore, a quantitative PDA approach should be applied in the EA design process.

\subsection{Integrated analysis framework}

Drawing on our explanation above, an integrated analysis framework is developed to specify the following aspects: drivers and benefits of combining EA design with PDA; the specific EA design process with PDA.

This research is driven predominantly by the lack of resource allocation oriented BITA research with EA, which lacks IT governance in the process of BITA achievement. Another driver roots in the incapability of designing an effective EA. Though EA is well admitted owning a huge superiority in organizations, it is likely to allocate resources and align different viewpoints through subjective decision making [46]. The complexities of the business environment and application landscape are also drivers of this paper [47]. Dynamic businesses and applications make nodes and their relationships turbulent. Additionally, various legacy applications that have been migrated and new applications that need to invest also compound the complexity.

As a result, the above questions can be mitigated through combining PDA with EA design. PDA helps strengthen the 
dependency of EA layers, and reorganize their relationships with a reasonable decision method. Consequently, a robust and effective BITA with EA can be built in this process.

A specific analysis framework is developed based on the EA design process. The framework seeks to address the above questions through several steps (business models de- sign, business functions extraction, candidate applications extraction, data collection, PDA, decision making, and system models design). The analysis process is not a onetime effort, which forms a continuous cycle with the dynamic external environments. Fig. 2 describes the drivers and benefits of the framework, and explains each step from focus, methods and deliverables.

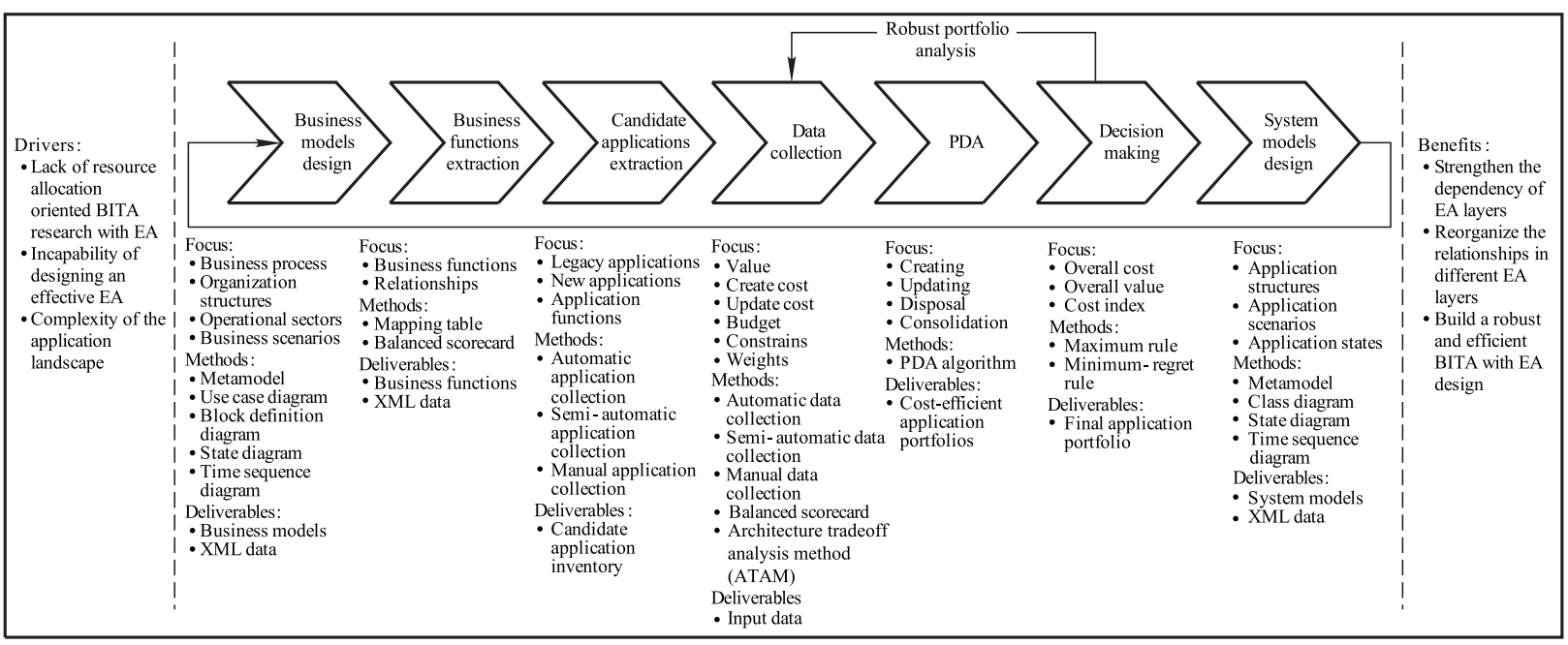

Fig. 2 An integrated analysis framework

(i) Business models design

According to strategic requirements of organizations, this step aims to design business models from business architecture. Business models vary with different EA frameworks. Among them, TOGAF mainly includes business functions, business process, business services, and business roles [43].

The above business contents can be modeled by different modeling techniques, such as use case diagrams, block definition diagrams, state diagrams, time sequence diagrams, and so on. These techniques output detailed business models and their XML data. Business models are built to gather complete business functions.

(ii) Business functions extraction

This step aims to elicit business functions based on above business models. Business functions can be represented by their names, enabled business activities and correlations. Extant EA frameworks (e.g., TOGAF, department of defense architecture framework (DoDAF)) use matrix or tables to map business functions with other business contents. Analysis methods, such as the balanced scorecard method, can be used to assess the importance of varied business functions. The outcomes of this phase are complete business functions and the corresponding XML data. (iii) Candidate applications extraction

The applications should be gathered to support business functions. Two categories of applications need to be listed: i) legacy applications, refer to the applications extracted from prior projects [45], which may be updated to support the above functions; ii) new applications, refer to newly introduced applications, which are invested by IT sectors or outsourcing. These two kinds of applications may support the same business functions. In addition, these applications should include features such as application name and application owner, and also involve operational performance, enabled business functions, and costs.

Therefore, this step exhibits three sub-steps: gather legacy applications that may support the business functions; consider new applications that organizations could introduce; determine the features of these applications. Three methods can be adopted to collect the above contents (automatic, manual, and semi-automatic). Automatic collection refers to the automation of reading source codes or databases. Manual collection obtains data directly by surveys and questionnaires. Semi-automatic collection integrates the above two methods and considers potential computational techniques.

(iv) Data collection

With complete business functions and applications, the 
relevant data should be collected next. The data is displayed as follows: legacy applications $L A$, new applications $N A$, legacy applications' updating costs $c(L A)$, new applications' creating costs $c(N A)$, the values of legacy applications or new applications $V(x)$, weights of business functions $\omega$, budget constraints cost, and synergy constraints of different applications $\operatorname{syn}(x, y)$ which indicates a cost discount when selecting synchronously.

Similarly, the data can also be collected by the above three methods (automatic data collection, semi-automatic data collection, and manual data collection). The outcomes of this phase are the input of PDA.

(v) PDA

In general, several strategies can be involved to search for feasible application portfolios [48]: the "creating" action invests on new applications; the "updating" strategy is used to strengthen legacy applications; the "disposal" action refers to discard non-selecting applications. The PDA method helps determine the strategies an application may receive. The formula is presented as follows:

$$
\left\{\begin{array}{l}
\max \sum_{i=1}^{n} \omega_{i} V_{i}(x) \\
\text { e.g. } \sum_{j=1}^{m} c\left(L A_{j}\right) x_{j}+\sum_{k=1}^{h} c\left(N A_{k}\right) x_{k}- \\
\sum_{p=1, q=1, p \neq q}^{m+h} \operatorname{syn}\left(A_{p}, A_{q}\right) \leqslant \text { cost, } x_{j}, x_{k}=1,0 \\
x_{L A_{p}}+x_{N A_{q}} \leqslant 1, \quad \exists L A_{p}, N A_{q} \text { meet } F_{i}, \\
p=\{1, \ldots, m\}, q=\{1, \ldots, h\}, i=\{1, \ldots, n\} \\
V_{i}(x)>0, \quad i=\{1, \ldots, n\}
\end{array}\right.
$$

Here, $m$ is the number of $L A ; h$ is the number of $N A$; $F$ represents functions; $n$ is the number of $F ; x_{i}$ means whether the $i$ th application is selected or not; meet represents that the applications can support the corresponding functions.

Based on the ample PDA research, we can choose suitable algorithms to solve the above equation. According to the collected data, the varied PDA algorithms are capable to deal with uncertain information (e.g., values, costs, weights) $[38,39]$ and make continuous feedback (e.g., robust analysis) [38]. We introduce a PDA algorithm proposed by Kangaspunta [42]. This algorithm mainly considers the incomplete data of weights, and has been applied to the weapon systems portfolio [42]. Multiple costefficient application portfolios are calculated due to the incomplete data.

(vi) Decision making
Further decisions need to be determined to compress the cost-efficient portfolios. There are mainly two approaches to acquire the optimal application portfolio. On the one hand, more exact data should be collected in the fourth step and a robust portfolio analysis [38] can be conducted to simplify the portfolios continuously. On the other hand, decision rules, such as the maximum rule and the minimum regret rule, can be adopted with regards to the overall cost, overall value, or the cost index of different applications.

(vii) System models design

Based on the optimal application portfolio, this step aims to design relevant contents in the information system architecture. These contents include application structures, application scenario, and application states. Generally, the above contents are modeled by different methods, such as class diagrams, state diagrams, and time sequence diagrams. The deliverables are system models and their XML files.

Overall, the consideration of IT resource allocation is deployed in the EA design process in this section. Their combination helps achieve a better alignment of business functions and applications. The method can be applied to various EA frameworks or other alignment patterns in EA.

\section{An illustrative case study}

This section aims to illustrate the above framework based on a common case of Switcher SA [32]. Switcher SA is a small private company engaged in the manufacturing and distribution of garments, from resource production to distribution of its products. Fritscher and Pigneur have developed business models of Switcher SA and built the alignment between business models and EA with an Archimate language [32]. Drawing on their study, the complete business contents and applications are displayed in this section.

Steps 1-3 According to the research of Fritscher and Pigneur [32], the business models of Switcher SA have been developed from the financial perspective, the customer perspective, and the process perspective. Three business functions are extracted to support organizational strategies: operations management, customer management, and innovation. Additionally, three kinds of applications are gathered to support businesses, which are transactional applications, informational applications and strategic applications. Each of them includes specific applications. According to the linkages between business processes and applications [32], mappings between business functions and the candidate applications are displayed as $\mathrm{X}$ in Table 2. Obviously, the cost-efficient application portfolio $\left(A_{1}-A_{13}\right)$ needs to be identified in the search of satisfying business functions $\left(F_{1}-F_{3}\right)$. 
Table 2 Mappings between business functions and applications in Switcher SA

\begin{tabular}{cccc}
\hline Application & $F_{1}$ : Operations management & $F_{2}$ : Customer management & $F_{3}$ : Innovation \\
\hline$A_{1}:$ Kookaburra & $\times$ & $\times$ & - \\
$A_{2}:$ System applications and products (SAP) & $\times$ & - & - \\
$A_{3}:$ Online store & $\times$ & $\times$ & - \\
$A_{4}:$ Collection catalogs & $\times$ & - & - \\
$A_{5}:$ Dashboard metrics data & $\times$ & - & - \\
$A_{6}:$ Optimiso & $\times$ & - & - \\
$A_{7}:$ Switcher color system & $\times$ & - & - \\
$A_{8}:$ Respect inside conformity website & $\times$ & $\times$ & - \\
$A_{9}:$ Business to business (B2B) platform & - & $\times$ & - \\
$A_{10}:$ Switcher friends & - & & - \\
$A_{11}:$ Web presence & - & $\times$ & \\
$A_{12}:$ Respect-code.org & - & $\times$ & $\times$ \\
$A_{13}:$ Respect inside community website & - & - & \\
\hline
\end{tabular}

According to [32], the legacy applications are assumed to contain $A_{1}, A_{2}, A_{4}, A_{5}, A_{9}, A_{10}$, and new applications are assumed to include $A_{3}, A_{6}, A_{7}, A_{8}, A_{11}, A_{12}, A_{13}$.

Step 4 This step collects relevant data in Fig. 2. Most of the data are assumed here. In order to obtain reasonable analysis results, the assumed data are required to meet the following rules:

(i) Applications with a higher supporting value for business functions may have a higher cost to update or create.

(ii) The applications which can support multiple functions may own a higher cost to update or create.

(iii) Values of legacy applications may be lower than those of new applications, so as to the cost.

Based on the above three assumptions, we assume that the legacy applications' updating costs are 800 , and values are 0.7 ; the new applications' creating costs are 1000 , and values are 0.8 . The unit is in dollars.

(iv) Synergy relationships of applications may exist, which indicate a discount of cost when selecting both of them. The synergy relationships and their cost discounts are assumed in Table 3.

Table 3 Cost discounts in synergy applications

\begin{tabular}{cccccc}
\hline & $A_{1}, A_{3}$ & $A_{5}, A_{6}$ & $A_{7}, A_{8}$ & $A_{1}, A_{9}$ & $A_{3}, A_{11}$ \\
\hline Discount & -100 & -100 & -200 & -100 & -100 \\
\hline
\end{tabular}

Therefore, the overall cost of an application's portfolio is calculated by (2) $(x=0,1)$. The budget cost is assumed as 8000 .

$$
\begin{gathered}
C(x)=800 x_{A_{1}}+800 x_{A_{2}}+\cdots+1000 x_{A_{13}}- \\
100 x_{A_{1}} x_{A_{3}}-\cdots-100 x_{A_{3}} x_{A_{11}} \leqslant \mathrm{cost}
\end{gathered}
$$

(v) In light of [32], there must be at least one application in each kind of applications to support corresponding functions. For example, $A_{1}, A_{2}, A_{3}$ are transactional applications to support $F_{1}$, and therefore at least one of them must be selected in the final application portfolio. These constraints are represented as the following formulas:

$$
\begin{gathered}
x_{A_{1}}+x_{A_{2}}+x_{A_{3}}>0, \quad x_{A_{4}}+x_{A_{5}}+x_{A_{6}}>0 \\
x_{A_{7}}+x_{A_{8}}>0, \quad x_{A_{1}}+x_{A_{3}}+x_{A_{9}}>0, \\
x_{A_{3}}+x_{A_{10}}+x_{A_{11}}>0, \quad x_{A_{12}}>0, \quad x_{A_{13}}>0 .
\end{gathered}
$$

(vi) The weights of business functions also need to be determined. Because point weights are difficult to be collected, the comparison relationships of the functions are assumed in (3). This is supported by the PDA algorithm with an extreme points method [42].

$$
\omega_{2} \geqslant \omega_{1} \geqslant \omega_{3}
$$

Step 5 With the above data and the PDA algorithm provided by Kangaspunta, 28 cost-efficient application portfolios have been acquired. These portfolios own a lower cost and higher overall value, holding approximately $4.4 \%$ of all the 640 feasible portfolios. The 28 portfolios are displayed in Table 4, and are used for further decision making.

Steps 6-7 Strategies should be adopted to get the final application portfolio from the above 28 portfolios. In terms of the maximum rule, $\mathrm{P} 26, \mathrm{P} 27$, or P28 can be selected, so is the case in the minimum-regret rule. The core index [38], which exhibits the frequency of applications in the portfolios, can be considered as a direct effect on the value of an application. Fig. 3 shows the core index of the 13 applications. It is observed that $A_{1}, A_{2}, A_{12}, A_{13}$ are the most prominent while $A_{6}$ receives the least emphasis. Therefore, $A_{1}, A_{2}, A_{12}, A_{13}$ are more likely to be selected in the final portfolio. Once the final portfolio has been determined, the other system models can be developed to help implement the development of EA. These, however, will not be introduced here. 
Table 4 Twenty-eight cost-efficient application portfolios

\begin{tabular}{|c|c|c|c|}
\hline Portfolio & Applications & Portfolio & Applications \\
\hline P1 & $A_{1}, A_{2}, A_{4}, A_{7}, A_{9}, A_{11}, A_{12}, A_{13}$ & $\mathrm{P} 15$ & $A_{1}, A_{2}, A_{6}, A_{7}, A_{8}, A_{11}, A_{12}, A_{13}$ \\
\hline $\mathrm{P} 2$ & $A_{1}, A_{2}, A_{4}, A_{8}, A_{9}, A_{11}, A_{12}, A_{13}$ & P16 & $A_{1}, A_{2}, A_{6}, A_{7}, A_{10}, A_{11}, A_{12}, A_{13}$ \\
\hline P3 & $A_{1}, A_{2}, A_{5}, A_{7}, A_{9}, A_{11}, A_{12}, A_{13}$ & P17 & $A_{1}, A_{2}, A_{6}, A_{8}, A_{10}, A_{11}, A_{12}, A_{13}$ \\
\hline P4 & $A_{1}, A_{2}, A_{5}, A_{8}, A_{9}, A_{11}, A_{12}, A_{13}$ & P18 & $A_{1}, A_{2}, A_{5}, A_{7}, A_{8}, A_{9}, A_{10}, A_{12}, A_{13}$ \\
\hline P5 & $A_{1}, A_{2}, A_{6}, A_{7}, A_{9}, A_{10}, A_{12}, A_{13}$ & P19 & $A_{1}, A_{2}, A_{3}, A_{4}, A_{7}, A_{9}, A_{10}, A_{12}, A_{13}$ \\
\hline P6 & $A_{1}, A_{2}, A_{6}, A_{8}, A_{9}, A_{10}, A_{12}, A_{13}$ & $\mathrm{P} 20$ & $A_{1}, A_{2}, A_{3}, A_{4}, A_{8}, A_{9}, A_{10}, A_{12}, A_{13}$ \\
\hline P7 & $A_{1}, A_{2}, A_{3}, A_{4}, A_{7}, A_{11}, A_{12}, A_{13}$ & $\mathrm{P} 21$ & $A_{1}, A_{2}, A_{3}, A_{5}, A_{7}, A_{9}, A_{10}, A_{12}, A_{13}$ \\
\hline P8 & $A_{1}, A_{2}, A_{3}, A_{4}, A_{8}, A_{11}, A_{12}, A_{13}$ & $\mathrm{P} 22$ & $A_{1}, A_{2}, A_{3}, A_{5}, A_{8}, A_{9}, A_{10}, A_{12}, A_{13}$ \\
\hline P9 & $A_{1}, A_{2}, A_{3}, A_{5}, A_{7}, A_{11}, A_{12}, A_{13}$ & $\mathrm{P} 23$ & $A_{1}, A_{2}, A_{5}, A_{6}, A_{8}, A_{9}, A_{10}, A_{12}, A_{13}$ \\
\hline $\mathrm{P} 10$ & $A_{1}, A_{2}, A_{3}, A_{5}, A_{8}, A_{11}, A_{12}, A_{13}$ & $\mathrm{P} 24$ & $A_{1}, A_{2}, A_{4}, A_{5}, A_{7}, A_{9}, A_{11}, A_{12}, A_{13}$ \\
\hline P11 & $A_{1}, A_{2}, A_{5}, A_{7}, A_{8}, A_{11}, A_{12}, A_{13}$ & $\mathrm{P} 25$ & $A_{1}, A_{2}, A_{4}, A_{5}, A_{8}, A_{9}, A_{11}, A_{12}, A_{13}$ \\
\hline P12 & $A_{1}, A_{2}, A_{6}, A_{8}, A_{9}, A_{11}, A_{12}, A_{13}$ & P26 & $A_{1}, A_{2}, A_{4}, A_{7}, A_{9}, A_{10}, A_{11}, A_{12}, A_{13}$ \\
\hline $\mathrm{P} 13$ & $A_{1}, A_{2}, A_{3}, A_{6}, A_{7}, A_{11}, A_{12}, A_{13}$ & $\mathrm{P} 27$ & $A_{1}, A_{2}, A_{4}, A_{8}, A_{9}, A_{10}, A_{11}, A_{12}, A_{13}$ \\
\hline P14 & $A_{1}, A_{2}, A_{3}, A_{6}, A_{8}, A_{11}, A_{12}, A_{13}$ & P28 & $A_{1}, A_{2}, A_{5}, A_{8}, A_{9}, A_{10}, A_{11}, A_{12}, A_{13}$ \\
\hline
\end{tabular}

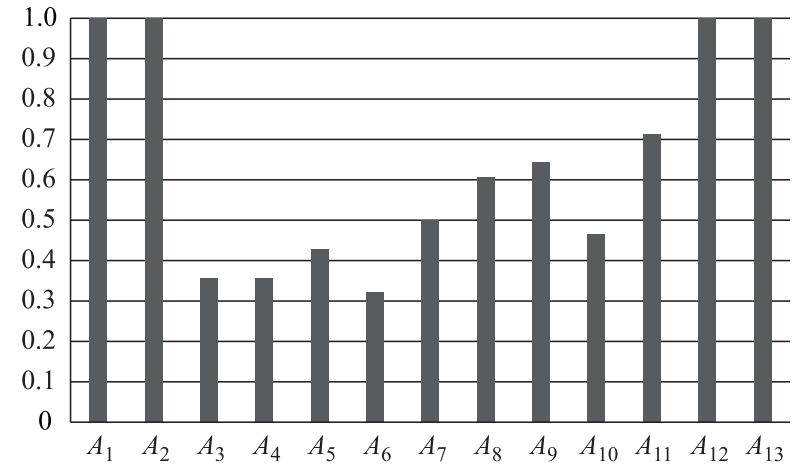

Fig. 3 Core indices of applications

Therefore, the proposed framework has been illustrated with the Switcher SA case in this section. An alignment of business functions and applications is achieved from the resource allocation perspective within the EA design process.

\section{Conclusions}

Given the insufficiency of extant EA studies in BITA, this paper elucidates the importance of IT governance in the design process of EA. From the perspective of IT resource allocation, this paper analyzes the alignment of business functions and applications, and applies the PDA method to the EA development. An illustrative Switcher SA case is conducted to explain the method's effectiveness.

We expect to contribute to the extant EA studies on improving IT governance capability. In particular, we combine the PDA method with the EA design process, and discuss how their combination can be executed in companies. This study also provides an important practical implication. The analysis helps maximize the return value of IT investments, and helps firms get a deeper understanding on EA development.

Limitations still exist in this study. Given the high re- quirement of data in the model, we have not explained where to gather the data from EA artifacts or databases. Additionally, a practical case is absent in our research. However, we believe the approach is a beneficial attempt to combine IT governance with EA design. The next step of our research will detailedly explain the data collection process, and examine a practical case study. Furthermore, the dynamic alignment will be considered under the turbulent business and IT environments. An extended dynamic resource allocation method will be discussed. Besides, the varied potential changes, and their governance mechanisms, will be taken into consideration.

\section{References}

[1] PARKER M M, BENSON R J, TRAINOR H E. Information economics: linking business performance to information technology. New Jersey: Prentice-Hall, 1988.

[2] BRANCHEAU J C, WETHERBE J C. Keyissues in information systems management. MIS Quarterly, 1987, 11(1): $23-$ 45.

[3] DIXON P J, JOHN D A. Technology issues facing corporate management in the 1990s. MIS Quarterly, 1989, 13(3): $247-$ 255.

[4] NIEDERMAN F, BRANCHEAU J C, WETHERBE J C. Information systems management issues for the 1990s. MIS Quarterly, 1991, 15(4): 475-500.

[5] HENDERSON J C, VENKATRAMAN N, OLDACH S. Aligning business and IT strategies. LUFTMAN J N ed. Competing in the information age, strategic alignment in practice. New York: Oxford University Press, 1996: 21 -42.

[6] AVISON D, JONES J, POWELL P, et al. Using and validating the strategic alignment model. The Journal of Strategic Information Systems, 2004, 13(3): 223-246.

[7] LUFTMAN J. Assessing business-IT allignment maturity. VAN GREMBERGEN W ed. Strategies for information technology governance. California: Idea Group Publishing, 2004: $99-128$.

[8] LUFTMAN J, KEMPAIAH R. An update on business-IT alignment: "a line" has been drawn. MIS Quarterly Executive, 2007, 6(3): 165-177.

[9] TRIENEKENS J J M, KUSTERS R J, CUENCA L. Measur- 
ing business-IT alignment, framework development and case study results. Information System Development, 2014: 1-16.

[10] WAGNER H T. Evolvement of business-IT alignment over time: a situated change perspective. Proc. of the 47th Hawaii International Conference on System Sciences, 2014: $4366-$ 4375.

[11] OHLSSON J, HAN S, HULTIN M, et al. How to achieve sustainable business it alignment-designing a circular organizational structure at SAAB. Proc. of the 49th Hawaii International Conference on System Sciences, 2016: 5116-5125.

[12] AMARILLI F, VLIET M, HOOFF B. An explanatory study on the co-evolutionary mechanisms of business IT alignment. Proc. of the 38th International Conference on Information, Systems, 2017: 1-21.

[13] PEREIRA C M, SOUSA P. Enterprise architecture: business and IT alignment. Proc. of the 2005 ACM Symposium on Applied Computing, 2005: $1344-1345$.

[14] ZARVIĆ N, WIERINGA R. An integrated enterprise architecture framework for business-IT alignment. https://core.acuk/ download/pdf/11470029.pdf.

[15] HINKELMANN K, GERBER A, KARAGIANNIS D, et al. A new paradigm for the continuous alignment of business and IT: combining enterprise architecture modelling and enterprise ontology. Computers in Industry, 2016, 79: 77-86.

[16] LUFTMAN J, BEN-ZVI T, DWIVEDI R, et al. IT governance: an alignment maturity perspective. International Journal of IT/Business Alignment and Governance, 2010, 1(2): 13-25.

[17] LUFTMAN J, LYYTINEN K, BEN ZVI T. Enhancing the measurement of information technology (IT) business alignment and its influence on company performance. Journal of Information Technology, 2017, 32(1): 26-46.

[18] GEROW J E, GROVER V, THATCHER J B, et al. Looking toward the future of IT-business strategic alignment through the past: a meta-analysis. MIS Quarterly, 2014, 38(4): $1059-$ 1085.

[19] WEGMANN A, BALABKO P, LÊ L S, et al. A method and tool for business-IT alignment in enterprise architecture. CAiSE Short Paper Proceedings, 2005: 113 - 118.

[20] WEGMANN A, REGEV G, RYCHKOVA I, et al. Business and IT alignment with SEAM for enterprise architecture. Proc. of the 11th Enterprise Distributed Object Computing Conference, 2007: $111-121$.

[21] SAAT J, FRANKE U, LAGERSTROM R, et al. Enterprise architecture meta models for IT/business alignment situations. Proc. of the 14th Enterprise Distributed Object Computing Conference, 2010: 14-23.

[22] PLAZAOLA L, FLORES J, SILVA E, et al. An approach to associate strategic business-IT alignment assessment to enterprise architecture. Proc. of the 5th Conference on Systems Engineering, 2007: $121-130$.

[23] SOUSA P, PEREIRA C, MARQUES J. Enterprise architecture alignment heuristics. Microsoft Architects Journal, 2004, 4: $34-39$.

[24] HENDERSON J C, VENKATRAMAN H. Strategic alignment: leveraging information technology for transforming organizations. IBM Systems Journal, 1993, 32(1): 472-484.

[25] WANG X Y, ZHOU X W, JIANG L B. A method of business and IT alignment based on enterprise architecture. Proc. of the IEEE International Conference on Service Operations and Logistics, and Informatics, 2008: 740-745.

[26] MALTA P, SOUSA R D. Process oriented approaches in enterprise architecture for business-IT alignment. Procedia Computer Science, 2016, 100: 888-893.

[27] ÓRI D. Misalignment symptom analysis based on enterprise architecture model assessment. IADIS International Journal on
Computer Science \& Information Systems, 2014, 9(2): 1- 15.

[28] ŐRI D. On exposing strategic and structural mismatches between business and information systems: misalignment symptom detection based on enterprise architecture model analysis. Budapest, Hungary: Budapesti Corvinus Egyetem, 2017.

[29] IACOB M E, QUARTEL D, JONKERS H. Capturing business strategy and value in enterprise architecture to support portfolio valuation. Proc. of the 16th Enterprise Distributed Object Computing Conference, 2012: $11-20$.

[30] BUCHANAN R D, SOLEY R M. Aligning enterprise architecture and IT investments with corporate goals. http://www. bptrends.com/publicationfiles/META\%200MG\%20WP\%20115-03.pdf.

[31] CHEN H M. Towards service engineering: service orientation and business-IT alignment. Proc. of the 41st Hawaii International Conference on System Sciences, 2008: 114.

[32] FRITSCHER B, PIGNEUR Y. Business IT alignment from business model to enterprise architecture. Proc. of the International Conference on Advanced Information Systems Engineering, 2011: 4-15.

[33] HINKELMANN K, PASQUINI A. Supporting business and IT alignment by modeling business and IT strategy and its relations to enterprise architecture. Proc. of the Enterprise Systems Conference, 2014: 149-154.

[34] ARTZNER P, DELBAEN F, EBER J M, et al. Coherent measures of risk. Mathematical Finance, 1999, 9(3): 203-228.

[35] SALO A, KEISLER J, MORTON A. An invitation to portfolio decision analysis. SALO A, KEISLER J, MORTON A ed. Portfolio decision analysis: improved methods for resource allocation. New York: Springer, 2011: 3-27.

[36] SHANE S A, ULRICH K T. Technological innovation, product development, and enterpreneurship in management science. Management Science, 2004, 50(2): $133-144$.

[37] KLINGEBIEL R, RAMMER C. Resource allocation strategy for innovation portfolio management. Strategic Management Journal, 2014, 35(2): 246-268.

[38] LIESIÖ J, MILD P, SALO A. Preference programming for robust portfolio modeling and project selection. European Journal of Operational Research, 2007, 181(3): 1488-1505.

[39] LIESIÖ J, SALO A. Scenario-based portfolio selection of investment projects with incomplete probability and utility information. European Journal of Operational Research, 2012, 217(1): $162-172$.

[40] SALO A, LIESIÖ J. A case study in participatory priority setting for a Scandinavian research program. International Journal of Information Technology \& Decision Making, 2006, 5(1): $65-88$.

[41] LINDSTEDT M, LIESIO J, SALO A. Participatory development of a strategic product portfolio in a telecommunication company. International Journal of Technology Management, 2008, 42(3): 250-266.

[42] KANGASPUNTA J, LIESIÖ J, SALO A. Cost-efficiency analysis of weapon system portfolios. European Journal of Operational Research, 2012, 223(1): 264-275.

[43] HAREN V. TOGAF Version 9.1. New York: Van Haren Publishing, 2011.

[44] HAREN V. Archimate 2.0 Specification. Berkshire, UK: The Open Group, 2012.

[45] MITLETON-KELLY E, PAPAEFTHIMIOU M C. Coevolution and an enabling infrastructure: a solution to legacy? HENDERSON P ed. Systems engineering for business process change, London: Springer, 2000: 164-181.

[46] NIEMI E, SAMULI P. Using enterprise architecture artefacts in an organisation. Enterprise Information Systems, 2017, 11(3): $313-338$. 
[47] TANRIVERDI H, LIM S Y. How to survive and thrive in complex, hypercompetitive, and disruptive ecosystems? The roles of is-enabled capabilities. Proc. of the 38th International Conference on Information Systems, 2017: 1-21.

[48] SIMON D, FISCHBACH K, SCHODER D. Application portfolio management - an integrated framework and a software tool evaluation approach. Communications of the Association for Information Systems, 2010, 26(3): 1-24.

\section{Biographies}

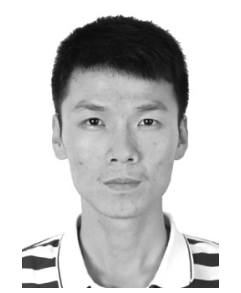

ZHANG Mengmeng was born in 1990. He is a Ph.D. candidate of Science and Technology at Information Systems Engineering Laboratory of National University of Defense Technology (NUDT) in China. He received his B.E. and M.S. degrees in management science and engineering from NUDT in 2012 and 2015, respectively. In 2016-2018, he was a visiting scholar with the Department of Design \& Innovation at the Case Western Reserve University in the United States. His research interests are the business-IT alignment and enterprise architecture design and management.

E-mail: 186703816365@163.com

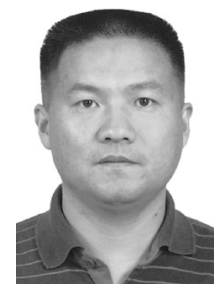

CHEN Honghui was born in 1969. He is a professor of management science and engineering, and director of science and technology at Information Systems Engineering Laboratory of NUDT in China. His major research interests are information systems and management, requirement engineering, and enterprise architecture management. He has published more than 30 journal and conference papers, and is-

sued two books.

E-mail: chh0808@gmail.com

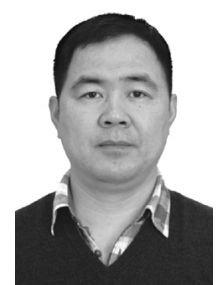

LIU Junxian was born in 1973. He received his M.Sc. degree and Ph.D. degree from NUDT. He is a professor in NUDT now. His current research interests include requirement engineering, military information system, and enterprise architecture design and analysis.

E-mail: 18674864900@163.com 